\title{
Conflictos de intereses en medicina. Recomendaciones del CETREMI
}

Miguel Ángel Celis, José Halabe, Oscar Arrieta, Rubén Burgos, Carlos Campillo, Manuel De la Llata, Judith Domínguez, Sergio Islas, Luis Jasso, Alberto Lifshitz, Mucio Moreno, Ricardo Plancarte, Alejandro Reyes-Sánchez, Guillermo J. Ruiz-Argüelles, Antonio Soda, Emma Verástegui y Julio Sotelo* Academia Nacional de Medicina de México, Comité de Ética y Transparencia en la Relación Médico-Industria, Ciudad de México, México

\section{Resumen}

Los conflictos de interés son situaciones en las que el juicio y la integridad de las decisiones o acciones médicas son influidas por un interés secundario, frecuentemente de tipo económico. El Comité de Ética y Transparencia en la Relación MédicoIndustria de la Academia Nacional de Medicina de México reconoce que estos conflictos ocurren en la vida diaria de los profesionales de la salud, pero también en las instituciones de servicios de salud públicas y privadas, así como en la academia y en la investigación. Por ello, es necesario identificar situaciones de conflicto y actuar siempre de acuerdo con el interés del paciente.

PALABRAS CLAVE: Conflicto de interés. Ética médica. Responsabilidad profesional. Código de ética.

\begin{abstract}
Conflicts of interest are situations in which judgment and integrity of medical decisions or actions are influenced by a secondary interest, often of an economic nature. The Committee of Ethics and Transparency in the Physician-Industry Relationship of the National Academy of Medicine of Mexico recognizes that these conflicts occur in health professionals' daily life, but also in public and private institutions that provide health services, as well as in the academy and in research activities. Therefore, it is necessary to identify conflicting situations and always act in accordance with the patient's interest.
\end{abstract}

KEY WORDS: Conflict of interest. Medical ethics. Professional responsibility. Code of ethics.

Los conflictos de intereses en medicina son reflejo de situaciones en las que el juicio y la integridad de decisiones o acciones médicas son influidas por un interés secundario, frecuentemente de tipo económico. Un médico, empresa o institución de salud incurre en conflicto de interés cuando en lugar de cumplir su función de acuerdo con la ética profesional o institucional, o de acuerdo a responsabilidades normativas y legales, sus decisiones 0 acciones son guiadas en beneficio propio o de un tercero. Estos conflictos pueden presentarse en numerosas decisiones de los profesionales de la salud.

Los conflictos de interés se desarrollan tanto en lo individual como en lo colectivo. En el ámbito de salud, los intereses comerciales influyen modificando el consumo de medicamentos y en la práctica institucional de agrupaciones científicas, a través de estrategias financieras de mercadeo. Un reflejo de ello es el exceso en la prescripción de medicamentos innecesarios y la extendida práctica de automedicación en la población,
Gac Med Mex. 2019;155:563-564 Disponible en PubMed www.gacetamedicademexico.com 
como resultado de campañas de publicidad en medios de comunicación. Ambas conductas pueden generar consecuencias indeseables en el paciente y en la salud colectiva, como interacciones medicamentosas o efectos adversos que originen padecimientos iatrogénicos.

También puede haber influencia de la industria farmacéutica y de insumos médicos en la investigación clínica, a través del financiamiento de ensayos clínicos con fármacos "innovadores" o "novedosos" dispositivos tecnológicos, privilegiando el interés comercial por encima del interés social. Igualmente, el interés farmacéutico financiero se da mediante la contratación de profesionales de la salud en la conducción de estudios, en su evaluación y aprobación en comités. De acuerdo con los resultados obtenidos en la investigación, la industria farmacéutica incluso apoya la publicación en revistas científicas.

Ante esta compleja interacción, en la sociedad se ha creado una imagen pública deteriorada de la ética de algunos profesionales de la salud (no solo médicos) que conviene analizar y atender, reforzando los principios de desinterés comercial y honestidad profesional del médico para que abonen a generar confianza en la sociedad sobre el profesional de la salud y una mejor relación médico-paciente.

Los intereses primarios de la medicina están claramente establecidos:

- La prevención de enfermedad y lesiones, así como la promoción y mantenimiento de la salud.

- Alivio del dolor y sufrimiento causados por enfermedad.

- La asistencia y curación de los enfermos y atención paliativa de quienes no puedan ser curados.

- Evitar la muerte prematura y velar por una muerte digna.

Recomendaciones del Comité de Ética y Transparencia en la Relación Médico-Industria:

- Evitar conflicto de interés en la práctica médica, en la relación entre médico y paciente por influencia de la industria farmacéutica y de insumos, así como por compañías de seguros de atención médica, que pudieran modificar los hábitos de prescripción en detrimento de la salud o del patrimonio económico del paciente.

- Impedir que empresas o instituciones relacionadas comercialmente con el médico influyan en la solicitud de exámenes innecesarios. Eliminar la dicotomía o participación de terceros en los beneficios financieros originados por intervenciones médicas o por solicitud de estudios.

- Oponerse a la presión de compañías de seguros sobre el profesional médico para abaratar costos, así como evitar estudios o procedimientos sin justificación, o en detrimento del bienestar del enfermo.

- No permitir la influencia de personal promocional en el juicio médico o en sus procedimientos. La interacción de los médicos con los representantes de la industria es ampliamente extendida, situación entendible, sin embargo, esas actividades pudieran introducir en el razonamiento médico un sesgo perturbador, proveniente de la persuasión de intereses financieros por encima de los del paciente, quien debe figurar siempre como el centro de atención.

- Evitar recibir obsequios o muestras médicas de los visitadores médicos.

- Evitar la influencia de pacientes o familiares para la prescripción de un determinado medicamento o autorización de procedimientos. Las decisiones médicas, en escenarios de incertidumbre diagnóstica, deberán ser tomadas en concordancia con la mejor práctica clínica basada en evidencias.

- Hacer conciencia (en la comunidad médica y en particular entre los jóvenes médicos y estudiantes) que ante la incertidumbre clínica y situaciones de potencial conflicto, debe evitarse que las decisiones médicas se orienten primordialmente a disminuir el riesgo de problemas legales, lo que fomenta la práctica de la medicina defensiva.

- Evitar que creencias religiosas o filosóficas influyan negativamente en la relación médico-paciente.

- Asegurar la independencia académica de las agrupaciones o sociedades médicas en la elaboración de programas de educación médica continua o congresos, sin influencia promocional de la industria farmacéutica o de insumos.

- Advertir en las revistas científicas el sesgo posible de estudios clínicos financiados por la industria, como una posible limitante en la información que puede desvirtuar el genuino interés médico-científico. 